\title{
Matemática y poesía: un recorrido por la métrica de León de Greiff
}

\author{
Mathematics and poetry: \\ a travel around León de Greiff's metrics
}

Enrique Ferrer-Corredor*

\begin{abstract}
Era música europea,
que transportada del otro lado del océano, se convirtió en cosa nueva [...].
\end{abstract}

Henriquez Ureña

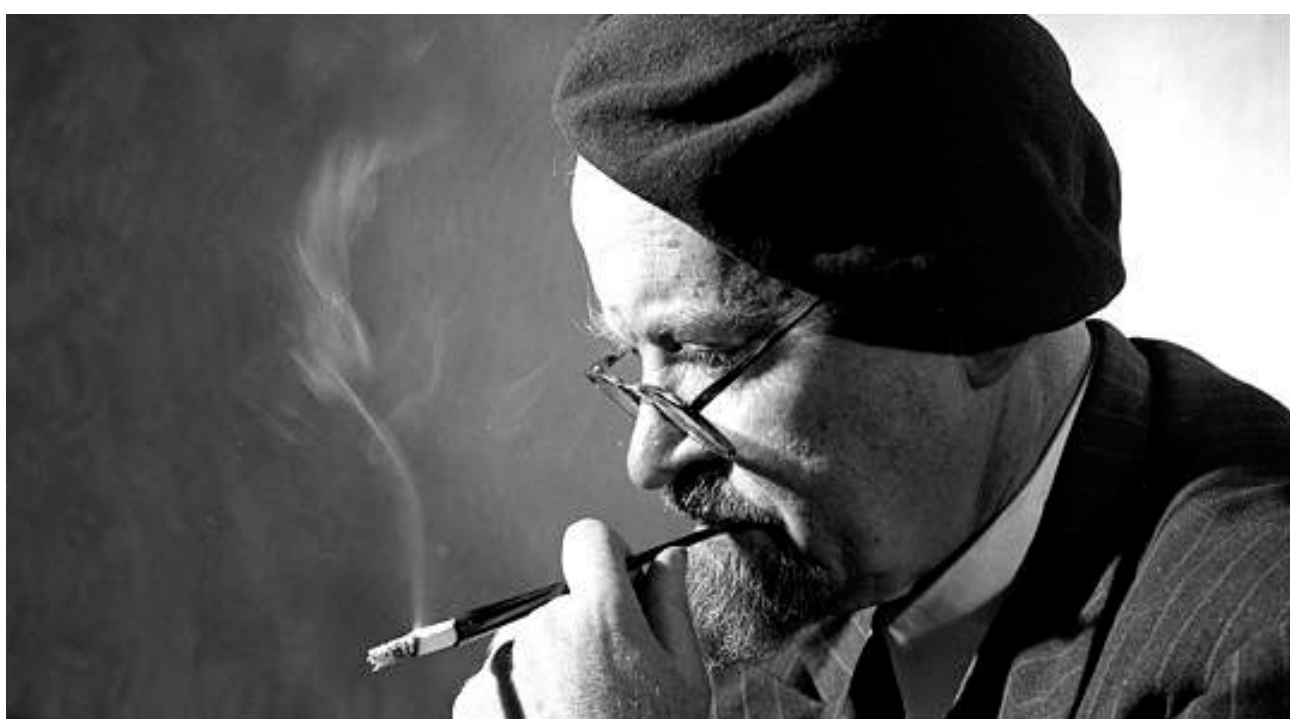

\section{Resumen}

Se desarrolla en este estudio una sensibilización con la técnica teórica de la métrica en aras de la comprensión de la propuesta estética de la poética de León de Greiff. En este caso, estudiamos los elementos del verso (silabación, ritmo acentual y encabalgamiento) en su poema "Trova del cazador de efímeros arreboles".

Palabras clave: métrica, León de Greiff, poesía.

Citar este artículo como: Ferrer-Corredor, E. (2016). Matemática y poesía: un recorrido por la métrica de León de Greiff. Revista Papeles, 8(16), 51-62.

Fecha de recibido: abril 10 de 2016.

Fecha de aceptación: junio 15 de 2016.

* PhD en Filología Hispánica de la UNED (Madrid, Esp.), MA en Literatura Hispanoamericana del Instituto Caro y Cuervo, licenciado en español-inglés de la UPN. Estudios de maestría en Ciencias Políticas de la Universidad de los Andes y estudios de economía en la Universidad Nacional. Docente de la UAN, ha sido docente de varias universidades en Colombia y los EEUU, entre otras la UPN, Externado, Universidad Nacional y la USB. Correo electrónico: enfer48@hotmail.com 


\begin{abstract}
This study develops a sensitization with the theoretical technique of metric in order to understand the aesthetic proposal of Leon de Greiff's poetics. In this case, we study the elements of the verse (syllabication, accentual rhythm, and ensemble) in his poem "Trova del cazador de efímeros arreboles".
\end{abstract}

Keywords: metrics, poetry, León de Greiff.

\title{
Introducción
}

La matemática nos invita a viajar al interior de un país donde desconocemos el paisaje, aunque ya pronto en la infancia, entre números y figuras aprendemos a imaginar secuencias, encuentros, asociaciones. Algunas veces los axiomas adquieren vida y leyes propias; otras, nos ayudan a desentrañar relaciones no visibles en la naturaleza, en nuestro pensamiento. La lengua con la que nombramos con precariedad el mundo funde y oculta procesos matemáticos expresados con palabras. Nos obliga la matemática a respirar con ritmo en nuestros pensamientos; esta cualidad captura relaciones de sucesiones y conteos de los símbolos de las cosas, es igualmente la esencia de la poesía en su forma, en su esencia sonora. La música de la poesía posee un pentagrama evolucionado desde el verso de la lírica medieval hasta el verso libre contemporáneo. El lenguaje matemático de la música, de la poesía, fluye como topologías sonoras en busca de sangre en las cosas que nombra. A lo mejor, los profesores de matemáticas lograrían persuadir mejor a sus estudiantes trocando el orden de la tradición si desde la música de la cosas, desde las sensaciones de la gente con su música y su poesía, enseñaran las formas matemáticas que las nutren.

Nos ocupa en este trabajo el análisis métrico de un poema de León de Greiff. La métrica es la geografía matemática de los sonidos de los versos. A veces, el mapeado de secuencias de números prefigura y funda realidad, produce el canon para hacer los versos; entonces, la realidad es interpretada desde su música por medio del lenguaje matemático. Incluso la lengua materna en sus recursos estilísticos y estructurales apela a la geometría, a la simetría, a complejas combinaciones matemáticas; estas formas tejen el álgebra de nuestra lengua para que nuestro lenguaje se anticipe al mundo.

La mayoría de los grandes escritores delatan sus deudas con las matemáticas en sus planes, en sus secuencias, en las formas estructurales de sus obras. No solo en la métrica de la poesía, sino incluso en las complejas estructuras de voces, tiempos y espacios de los cuentos y de las novelas. Dante es un ejemplo excelso de geometría aplicada al mundo imaginado:

Dante's Paradiso is built on the plan of Aristotle's On the Heavens. That Christians might conceive of the world this way was established in the theology of Thomas Aquinas in Dante's own lifetime. Aquinas doesn't explicitly describe Aristotle's universe, but he adopts its terms in speaking about the arrangement of things, which amounts to an implicit acceptance of it. He considers the question of the Earthly Paradise, for example, and whether it might be located as high up as just under the sphere of the Moon (Peterson, 2011).

En nuestro caso, exponemos las técnicas métricas de León de Greiff en su poema "Trova del cazador de efímeros arreboles" en busca de los vasos comunicantes entre la poesía y la matemática. Vamos a recorrer los recursos sonoros métricos dispuestos por el poeta. La extensión del poema nos hace elegir apenas la primera estrofa para recorrer tres instancias de los conceptos básicos del análisis métrico estructural: el silabeo, los acentos y el encabalgamiento. 


\section{Entorno métrico en la obra de León de Greiff}

Los críticos resaltan la individualidad poética de León de Greiff en la gran variedad de formas líricas y léxicas expresadas en las innovaciones desde las formas métricas tradicionales de versificación, la experimentación de nuevos moldes de rima y ritmo, la adaptación poética de la música sinfónica, la exuberancia léxica, los juegos acústicos. Su rebeldía poética estuvo emparentada con su actuar en la vida: tras los acontecimientos de "el bogotazo" del 9 de abril de 1948 fue llevado a la cárcel acusado de ocultar publicaciones que incitaban a la rebelión.

En la perspectiva de la estética formal a nivel discursivo en la poesía greiffiana, "El sinfonismo" parece ser un término propio para describir el estilo de cierto grupo de sus obras, en las que el poeta intenta interpretar o igualar las normas de la música clásica y la poesía. Sobre este punto se trabajará y ampliará en esta investigación.

El sinfonismo ilustra los nexos entre música y poesía en León de Greiff, e incluso en un sentido filosófico de sus formas estéticas, su referencia a los preludios. El preludio nació como una improvisación breve del lautista, organista $\mathrm{u}$ otro músico solista al intentar tocar y afinar su instrumento. De Greiff adopta estas formas comenzando con las formas más libres. Titula varios de sus poemas "preludio", y la mayoría de estos se parecen a la primera sección de una composición más larga. El preludio indica que no hay restricciones formales, acercándose a menudo a una improvisación y funcionando como una unidad independiente.

La poesía greiffiana nos invita a los malabares de sonidos con palabras, es el canto a la vida lleno de música y colores de todas las geografías. Un poema del poeta manifiesta sus malabares consonánticos: "Balada de asonancias consonantes o de consonancias

\section{El sinfonismo ilustra los nexos entre música y poesía en León de Greiff, e incluso en un sentido filosófico de sus formas estéticas, su referencia a los preludios.}

disonantes o de simples disonancias" ${ }^{1}$. Si bien Silva nos abrió las puertas a la modernidad poética, León de Greiff nos tendió el puente a la vanguardia. Ocupa un lugar excepcional en nuestra historia poética. Su valoración siempre deberá tener en la cuenta la parsimonia histórica de nuestro país, tanto en el arte como en otros órdenes, para asumir los cambios y los nuevos horizontes... "ningún maestro de la rima, antes que León entre nosotros, se preocupó jamás (si acaso Silva) por ensanchar los horizontes reservados al verso" (Vásquez, 1943, p. 397).

No obstante, pese a su bohemia y a su sentido del humor, León de Greiff asume el mundo moderno con sus contradicciones (la contradicción de la especialización del trabajo frente al ser artista, el hecho de ganarse el pan en una oficina mientras alterna su trabajo como poeta, los desencuentros estéticos con sus generaciones contemporáneas, etc.); este equilibrio-desequilibrio lo lleva a evitar la poesía almibarada y cantarina del peor modernismo. Este hecho va a ser apreciado por algunos críticos.

El temperamento esencialmente intelectual de León de Greiff le preservó de la vocinglería almibarada y machacona de los románticos del rosal y la fontana cantarina y el cristal claro y

Es famosa la anécdota de 1956 en que no podía convencer a los policías de que los apuntes que llenaban sus bolsillos no eran consignas en clave, ni planes secretos conspiradores. 
los dones tempraneros de la princesa Primavera. Y espero verle desempeñarse, adelante, en el problema religioso, en las arduas labores del concepto de familia, en la aspiración de la grandeza y de la gloria inequívocas en el servicio de la Patria y de la Humanidad conjuntamente, desentendido por completo de las bellaquerías poéticas del amor al uso que, si mucho no me engaño, deben ser consideradas como el mariquismo de la poesía (Farina, 1920, p. 22).

El espacio literario en León de Greiff se construye a través de artificios formales, cuya repetición delimita la estética del poeta. Orlando Rodríguez Sardiñas nos resume estos recursos así:

Las irregularidades métricas descienden directamente de la tradición literaria que le acompaña y que ya ha utilizado metros heptasílabos y pentasílabos, versos con estrambote y pie quebrado; estrofas asimétricas de dodecasílabos y decasílabos con variaciones del yámbico, del sáfico, del anapéstico, etc., todas ellas usadas por poetas de todas las épocas. No será aquí donde resida la fama de poeta extraño que tiene de Greiff. Búsquese en la utilización de ciertos recursos formales, en los vocablos empleados, en las categorías verbales, en los adjetivos y en las metáforas y símbolos, pero sobre todo en esa atmósfera lírica, en esa inmaterialización de la realidad, de lo visto y oído, que hace que los sentidos se salgan del cauce normal en el que se justifica lo real y - volviendo al principiodonde el factor causal es la sola palabra poética (Rodríguez, 1972, p. 528).

$\mathrm{Al}$ anterior horizonte métrico de su obra se suma el empleo de un vocabulario 'exótico' y original en aras del juego semántico-sintáctico y en el ámbito de construir cadenas sonoras: música y poesía, verbo y clave, dolor y burlas, rictus y pirueta. El sentido cifrado recuerda la herencia de los mecanismos de poetas del siglo XIX, en particular, las teorías de construcción poética de Edgar A. Poe.
The evolution of De (sic) Greiff's literary lexicon over the six decades of his writing career is shown to involve enrichment of his vocabulary, and movement away from formality to the bolder, less restrained style of the latter part of his production. It is observed that his implicit literary theory, as manifested in the entire corpus of his writings, relates in many ways to that of Poe's "Poetic Principles" (Mohler, 1969, p. 25).

La propuesta estética de León de Greiff fluctúa entre el horizonte posmodernista y la construcción de la vanguardia en Colombia, hecho que se revelará de un modo explícito en su experimentación métrica. Existe una multitud de ejemplos en este sentido, debido precisamente a la relativa indefinibilidad de las vanguardias hispanoamericanas: así el colombiano León de Greiff, en cuya poesía se encuentran elementos marcadamente posmodernistas (musicalidad, humor, parodia); no obstante, se le otorga un lugar prominente en la configuración de la vanguardia en Colombia.

Un autorretrato del poeta nos revela su arte "poética", su necesidad de definición y delimitación de un mundo moderno propio:

Si es un retrato mío, aqueste vala: belfa la boca de hastiado gesto si sensual, ojos griseos, con un resto de su fulgor - sonantes, de adehala todavía -. La testa sin su gala pilosa. El alta frente. Elato Enhiesto.

El conjunto: mitad Faltaff (si honesto) mitad skalde prófugo de Uppsala. Hacia el subfondo, el caso lo complico de este jaez: filósofo a la gabe, bufón a la sarcástico...; ¿poeta? Poeta..., en ocasiones, aunque imbrico música y poesía, verbo y clave, dolor y burlas, rictus y pirueta. 


\section{Estructura de este análisis métrico}

Los apartados precedentes nos ilustraron sobre los aspectos generales de la métrica y sobre las características generales tanto de la obra como de la crítica alrededor de León de Greiff. Así, la estructura que sigue precisa los aspectos técnicos del análisis textual métrico (se toma como base la estructura del libro de José Domínguez Caparrós en Métrica Española).

\section{A. Elementos del verso:}

De acuerdo con Domínguez Caparrós el verso es unidad rítmica, se repite y forma series; estas unidades pueden ser semejantes y desemejantes. Los factores rítmicos del castellano son: la sílaba, el acento, la pausa y el timbre; categorías que sirven para clasificar los versos. Así, pensar en el ritmo se relaciona con tres aspectos: la repetición simétrica, las relaciones estéticas de los componentes lingüísticos del verso y la tipificación del verso en relación con el esquema global del poema. La situación está en la propuesta de un esquema textual como sistema rítmico.

\section{B. Clases de verso:}

Los elementos del verso constituyen "formas hechas", repeticiones rítmicas. Esa amplia y compleja variedad de formas rítmicas nos lleva al inventario de clases de versos. Estos los puedo clasificar de acuerdo con criterios como: verso regular e irregular; arte mayor o menor; regularidad en el número de sílabas y clase de verso español; verso tónico y la distribución de los acentos; verso clásico y verso libre.

\section{Combinaciones métricas:}

Más allá de las unidades constitutivas del verso y sus clases: el conjunto de versos que constituye la manifestación métrica concreta se presenta normalmente organizado de acuerdo con una estructura. Puede ocurrir que el poema ordene los elementos rítmicos con arreglo a un patrón estructural de simetría que se repite a lo largo del mismo; y estamos entonces ante una "combinación métrica estrófica”. Puede ser también que el esquema de composición del poema esté fijado de antemano; en ese caso se tiene una "forma de composición fija". Si la disposición del poema no repite ningún esquema, nos encontramos ante "series no estróficas".

\section{Nota sobre la muestra del poeta}

Nos ocupa en esta muestra un poema de León de Greiff: “Trova del cazador de efímeros arreboles". Este poema se inscribe dentro de la propuesta estética del verso libre y semi-libre: el poema presenta una gran irregularidad, tanto en el verso como en la composición estrófica.

Este poema representa de un modo significativo la postura estética del León de Greiff: la influencia de las vanguardias europeas y los tiempos de librepensamiento en un ámbito de gran juego con estructuras musicales. Incluso, y esto generó confusión entre sus primeros lectores, en ocasiones es clara la prelación de los juegos de palabras en aras de la lúdica de los sonidos y de las imágenes, frente a alguna preocupación por un concepto acabado.

El exótico temario de los poemas combina las referencias a la vida de bohemio, viajero y poeta; el hombre de refinados gustos 'naturales' con la alusión a temas de diversos y distantes lugares, creando una atmósfera de hombre de mundo. Este hecho es relacionado por algunos críticos (ya mencionaré las fuentes) como uno de los tanto vínculos del poeta con el modernismo, negándole el carácter de vanguardista. 


\section{Una nota sobre el horizonte conceptual}

Antes de entrar en el capítulo del análisis métrico propiamente, debo expresar (como ya lo han dicho diversos teóricos) que aguardo muchas dudas aún sobre el proceso técnico, que es dispendioso y requiere de arduo trabajo para su dominio. En particular para la toma de decisiones analíticas entre la diversidad teórica. Enumero los conceptos que más dificultades producen dudas de aplicaciones teóricas en el ámbito de los versos no tradicionales de León de Greiff: silabación y conteo acentual, sinafía, semirra, grupos fónicos, fragmentación, criterio de estrofa y unidades acentuales, criterios para una métrica estética, criterio para una métrica comparada, etc.

\section{Análisis métrico textual del poema "Trova del cazador de efímeros arreboles"}

\section{Elementos del verso}

Silabación:

-Las licencias métricas

-Equivalencia de finales de verso

-El ritmo acentual y la sílaba

La pausa:

-Pausa y ritmo

-Clases de pausa

-Encabalgamiento

La rima:

- Rima consonante y asonante

-Estilística de la rima

-Lugar y disposición

El acento:

—Análisis métrico y clases

-El ritmo acentual

-Acento y versificación

Número y clases de versos:

-Número de versos

-Versos de arte mayor y hemistiquio

- Tipos de verso regular

-Verso libre

-Combinatoria de versos

Combinaciones estróficas:

-Límites y conceptos

- Frases funcionales de las estrofas

-Estribillos

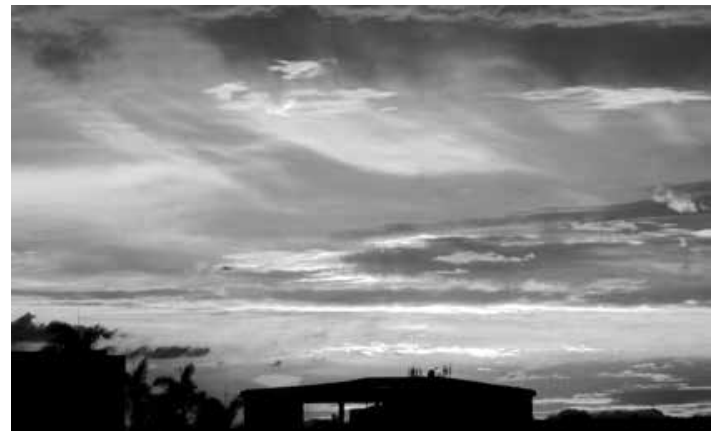

\section{"Trova del cazador de efímeros arreboles"}

¿Es ésta entonces la ávida vida abierta a todos los insólitos vientos del azar, a todos los sólidos vientos

Pregustados?

¿Es ésta?

¿Y aquí pensé encallar?

¿Aquí pensé afincar el ancla?

la vagabunda nao?

¿y, por siempre, fijar

-Para, con la ánima despierta, y en el tufo salino y en los vientos insólitos, desaforados, turbulentos, (con sutil oído, con la aguda nariz - unánimes [acólitos -)

¿captar, captar, captar

la ciencia del fugado mar?

¿Es ésta, es ésta, ánima mía, 
corazón mío, espíritu mío, -sitibundos-, corazón mío, espíritu mío -errantes-, frenéticos, vagabundos, vaga mundos desalados, -es ésta, es ésta entonces la ávida vida, soberana de toda la cosa terrena y de la sideral y de lo [que ideó el ensueño?

La ávida vida abierta, como los fijos ojos horadantes y como los oídos -caracoles [profundosy el pensieroso ceño,

y la frente, -campana:

y la frente-campana- para albergar los [aladíneos despojos de las piraterías y los asaltos inverecundos: los sables de abordaje -azules- de sangre [rojos; los labios -rojos-azules de mares y mundos; los dedos enjoyados de acariciar la hembra (en [cuyos lientos, madorosos, musgosos refugios perfumados descubrieran maravillosos Eldorados y de abenuz y múrice deleitables portentos...)

Es ésta, es ésta, ánima mía sitibunda, corazón mío, espíritu mío -ardientes, insaturables, inextinguibles, indómitos, [eternos insurgentes-, ¿Es ésta entonces la ávida vida soberana, y soberana de toda la cosa terrenal y sideral, [o que soñó- cogitabundala grávida campana pletórica de fantasías indehiscentes?

La ávida vida abierta como los horadantes fijos ojos insomnes y vigías y los oídos, caracoles, y la frente, campana:

y la boca, que el mar hurtó salobre aliento; y la melena, ansia de fugas a los vientos [errantes; y el espíritu, al mar y al viento y a los soles de oro y a las noches de terciopelo endrino, -la libertad, la música recóndita y el encanto [marino:

¡Oh cazador de efímeros arreboles!

¡Oh cazador de efímeros arreboles, de bocas y de ensueños que el deseo satura de no sabido hechizo!

¡Oh cazador de arreboles efímeros, de espíritus y sexos que el deseo enaltece -transitorio- y que abaja el hastío; oh cazador de nubes, navegador de nubes, cabalgador de sombras, propugnador del

domeñador de vientos!

[olvido,

¡Oh cazador de arreboles efímeros, argonauta en océanos de sónes, y en piélagos de ritmos argonauta, y en las noches de pasión y de sexüales...!

[perfumes

¡Oh noches de terciopelo endrino...!

¿Es ésta entonces la ávida vida abierta y a todos los milagros y a todos los portentos y maravillas?

¿y a toda la cotidiana cosecha pregustada?

¿O a lo que sembró el azar?

$¿ \mathrm{O}$ a todos los prodigios y a todos los mirajes embaidores, y espejismos aladinescos, y

e indehiscentes fantasías?

[señuelos,

¿Es ésta, es ésta,

ánima mía,

corazón mío, espíritu mío? -ijamás, jamás [saciados!-,

corazón mío, espíritu mío -¡satisfechos

[nunca!-, ¿Es ésta entonces la ávida vida de mis sueños, la ávida vida soberana de toda la cosa terrena y sideral o que ideó mi cogitar?

¿Es ésta?

¿Es ésta?

¿Y aquí pensé encallar? 


\section{Elementos del verso}

Silabación: División en sílabas, distintos aspectos de la sílaba (hiato, sinalefa, sinafía), equivalencia de finales esdrújulos, graves y agudos.

\section{"Trova del cazador de efímeros arreboles"}

¿Es-és-taen-ton-ces-la-á-vi-da-vi-daa-

bier-ta

Sinalefa en (taen) y en (daa).

Hiato en (la) (a) por acento rítmico

marcado en la segunda vocal.

Duda en es-es-ta... ó e-ses-ta.

a-to-dos-los-in-só-li-tos-vien-tos-del-

A-zar,+

Se le agrega una sílaba porque el

verso termina en palabra aguda.

Sinafía entre el $1^{\circ}$ y $2^{\circ}$ verso

(restamos esa sílaba).

a- to-dos-los-só-li-tos-vien-tos

pre-gus-ta-dos?

¿Es-és-ta?

¿Ya-quí-pen-séen-ca-llar?+

Sinalefa en (ya) y en (séen).

Se le agrega una sílaba porque el verso termina en palabra aguda.

¿A-quí-pen-séa-fin-car-el-an-cla?

Sinalefa en séa.

¿Y,-por-siem-pre,-fi-jar?+

Se le agrega una sílaba porque el

verso termina en palabra aguda.

Sinafía.

la-va-ga-bun-da-na-o?

- ¿Pa-ra,-con-la-á-ni-ma-des-pier-ta,

Hiato en (la) (á) por acento rítmico marcado.

Yen-el-tu-fo-sa-li-no-yen-los-vien-tosin-só-(li)-tos,
Hiato en (no) (yen) por vocal intermedia cerrada, rodeada de vocales abiertas.

Sinalefa en (yen).

Se le resta una sílaba porque termina en palabra esdrújula.

De-sa-fo-ra-dos,-tur-bu-len-tos, (con-su-til-o-í-do,-con-laa-gu-da-na-

riz- -u-ná-(ni)-mes

Sinalefa en (laa).

Se le resta una sílaba porque termina en palabra esdrújula.

a-có-(li)-tos -)

Se le resta una sílaba porque termina en palabra esdrújula.

cap-tar,-cap-tar,-cap-tar+

Se le agrega una sílaba porque el verso termina en palabra aguda.

la-cien-cia-del-fu-ga-do-mar?+

Se le agrega una sílaba porque el verso termina en palabra aguda.

\section{Nota:}

Resulta más ilustrativo un pequeño análisis de la geografía combinatoria del poema. No hay definición estricta de estrofa, lo que en un análisis de longitud del verso y tipo de verso dificulta los conceptos de agrupación y definición de ritmo, como repetición, en este caso, de los periodos versales y estróficos. No obstante, justamente, en el ámbito de esta irregularidad, se percibe un juego entre el verso largo y el corto, así como entre la cuasi-estrofa y las frases conectoras entre ellas (en muchos casos compartidas), como la primera vez que se pronuncia: ¡Oh cazador de efímeros arreboles!

\section{Ritmo acentual ${ }^{2}$}

En este aparte sobre el ritmo acentual, dado el carácter de verso libre y semilibre manejado por León de Greiff, se hará un estudio entre descriptivo y analítico-comprensivo de la

2 Los acentos por pies podrán ser útiles y por ello realizamos una nota para recordar algunos de sus aspectos. Sin embargo, como ya se dijo, Greiff actúa a la manera del músico en un preludio, prueba combinaciones, juega con las series de sonidos. NOTA: Acentos por pies: Trocaico: tónica/ átona. Yámbico: átona/tónica. Anfíbraca: átona/ tónica/átona. Dactílica: tónica/atona/atona. Anapéstica: atona/atona/tónica. 
distribución e intencionalidad estética del poeta.

El acento es un elemento fundamental del ritmo del verso, hasta el punto de que los factores que definen el esquema (el metro) de las principales clases de versos, como se verá, son el número de sílabas y el número y lugar de los acentos (Domínguez, 2000, p. 81).

En palabras de Domínguez Caparrós, en la métrica española, "por influencia del esquema rítmico, de la música y de la rima, se producen: desplazamientos del acento de la palabra, acentuación en sílabas átonas, doble acentuación de polisílabos, acentuación de monosílabos, desacentuación de sílabas tónicas" (Domínguez, 2000, p. 82). Se observan en el poema "Trova del cazador de efímeros arreboles" diversos fenómenos combinados en la propuesta rítmica de la poesía de León de Greiff. Algunos de estos fenómenos y licencias métricas ya fueron señalados en el apartado anterior: la invención de palabras por la conveniencia de sonoridad, la ruptura sintáctica para lograr efectos sonoros, la combinación de periodos métricos internos, la reiteración silábica interna, la aparición de hemistiquios. De un modo particular, el hecho más relevante para nuestro propósito alrededor del ritmo acentual: la combinación de versos yámbicos y trocaicos (y otros casos de acento final de verso y los casos especiales de los endecasílabos), la alternancia experimental de los pies acentuales y la invención de periodos inéditos.

Este trabajo requiere de una formulación de modelos de explicación de la forma en que se organiza el acento en el verso español. Se requiere "el reconocimiento de unidades rítmicas formadas por grupos interiores de sílabas métricas en torno a un acento [...] de un patrón llamado cláusula rítmica o pie acentual" (Domínguez, 2000, p. 85). Un estudio de esa magnitud desborda los alcances de este artículo.

\section{Descripción de la distribución} acentual ${ }^{3}$ :

\section{"Trova del cazador de efímeros arreboles"}

¿Es ésta entonces la ávida vida abierta

$2 \quad 4 / 25 \quad 5 \quad 7$

a todos los insólitos vientos del Azar,

$\begin{array}{llll} & \prime & & \\ 2 & 6 & / 1 & 5\end{array}$

a todos los sólitos vientos

$\begin{array}{lll} & ' & \\ 2 & 5 & 8\end{array}$

pregustados?

3

¿Es ésta?

2

¿Y aquí pensé encallar?

$2 \quad 4 \quad 6$

¿Aquí pensé afincar el ancla?

$$
\begin{array}{llll}
2 & 4 & 7 & 9
\end{array}
$$

¿y, por siempre, fijar

36

la vagabunda nao?

$$
46
$$

-¿Para, con la ánima despierta,

$$
1 \quad 5
$$

y en el tufo salino y en los vientos insólitos,

$36 / 36$

3 Aclaración: En este segmento sobre el acento requiero de mayor investigación y apoyo para seleccionar la teoría más adecuada y aplicar con los mejores criterios. En particular sobre las categorías a utilizar. 
desaforados, turbulentos,

$$
4 \quad 8
$$

(con sutil oído, con la aguda nariz - unánimes

$\begin{array}{cccccc}3 & 5 & 9 & 2 \\ & & & \\ & & & 6 \\ & & & \end{array}$

$$
\begin{array}{crr}
\multicolumn{3}{c}{\text { captar, captar, captar }} \\
2 & 4 & 6
\end{array}
$$

la ciencia del fugado mar?

$$
2 \quad 6 \quad 8
$$

\section{Encabalgamiento y pausas ${ }^{4}$}

León de Greiff en su poética recurre a diversas pausas al interior del verso, incluso entre versos, en la búsqueda de efectos métricos. Estos recursos se distribuyen ya sea en el verso, en la cesura en los versos de arte mayor y mediante alteraciones sintácticas.

La pausa es un fenómeno métrico inseparable del sentido del ritmo en el verso. Justamente, ésta define en buena medida la fragmentación del discurso poético. La segmentación rítmica del lenguaje se reconoce delimitada por pausas métricas (Domínguez, 2000, p. 99).

Las principales pausas internas en "Trova del cazador de efímeros arreboles" son: el uso de paréntesis, la repetición de categorías sintácticas separadas por signos de puntuación, la distribución de acentos, el uso de palabras semánticamente 'menores' (preposiciones y conjunciones), uso de oraciones interrogativas, entre otras.

De otro lado, León de Greiff recurre a la organización morfosintáctica, más allá de la estructura del verso, incluso en su caso, abundante en la combinación entre versos cortos y largos, con una métrica cercana al verso libre, aunque con marcas periódicas características. Es difícil fijar los límites precisos para el encabalgamiento, en ocasiones los grupos de

4 Como lo cita el profesor José Domínguez Caparrós, el concepto de encabalgamiento ofrece diversas interpretaciones. palabras y las normas de la lengua hablada no permiten separar con un descanso. "Muchas veces el descanso del verso se organiza en concordancia con la pausa morfosintáctica, pero otras no. Cuando se da el desajuste entre la pausa versal y la sintáctica, se produce el fenómeno estilístico conocido como encabalgamiento" (Domínguez, 2000, p. 103).

\section{Algunos tipos de encabalgamiento}

El encabalgamiento es un fenómeno sintácticosemántico relacionado con la cadencia entre los versos. Las secuencias oracionales a veces, en otros casos proposicionales, o ambas, son objeto de manipulaciones lúdicas por parte del poeta para lograr la fluidez del canto. Tomamos estos conceptos básicos del libro ya mencionado, Métrica española (Domínguez, 2000, p. 104):

Versal: Al final del verso: La ávida vida abierta como los horadantes / fijos ojos insomnes $y$ vigías

Abrupto: No pasa de la quinta sílaba del verso encabalgado: argonauta, y en las noches de pasión y de perfumes / sexuales...!

Suave: Pasa de la quinta sílaba: La ávida vida abierta como los horadantes / fijos ojos insomnes

Oracional: Si se separan el antecedente y el pronombre de una oración adjetiva: ¿La ávida vida soberana / de toda la cosa terrena y sideral o que ideó mi cogitar? 
Sirremático: Si se trata de una separación en el interior de los otros grupos: ¿Es ésta entonces la ávida vida abierta / a todos los insólitos vientos del Azar, a todos los sólitos vientos / pregustados?

\section{Enlaces sintáctico-semántico entre versos}

"Trova del cazador de efímeros arreboles" ¿Es ésta entonces la ávida vida abierta a todos los insólitos vientos del Azar, a todos los sólitos vientos pregustados?

¿Es ésta?

¿Y aquí pensé encallar?

¿Aquí pensé afincar el ancla?

la vagabunda nao?

$$
\text { ¿y, por siempre, fijar }
$$

- ¿Para, con la ánima despierta,

y en el tufo salino y en los vientos insólitos,

desaforados, turbulentos,

(con sutil oído, con la aguda nariz - unánimes [acólitos-)

captar, captar, captar

la ciencia del fugado mar?
Léxico: Si se divide una palabra. Sólo encontraos algunos casos muy cercanos: La ávida vida abierta, como los fijos ojos / horadantes y como los oídos -caracoles /
E. suave

E. suave

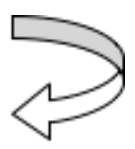

cabalgante

v. Encabalgado

v. Encabalgante

v. Encabalgado

E. suave

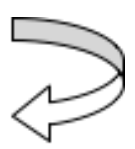

v. Encabalgante

v. Encabalgado

v. Encabalgado
E. suave

E. suave

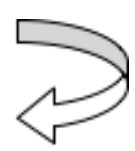

\section{Rima: (consonante y asonante) y musicalidad en general.}

La rima es un elemento esencial en la conjunción entre poesía y métrica. La rima marca en muchos casos los límites del verso, las series rítmicas y el ámbito de las estrofas. De Greiff recurre tanto a la rima asonante (solo coinciden las vocales a partir de la tónica) como a la consonante (cuando coinciden todos los sonidos a partir de la última vocal tónica) en su afán de construir equivalencias sonoras, ritmos e incluso sentido.

La función rítmica de la rima está en relación con su carácter reiterativo. $\mathrm{Y}$ es esta reiteración la que contribuye a la organización del verso en grupos estróficos. Por otra parte, del carácter reiterativo se deriva su contribución a la función poética: en la rima se contraponen, o se asocian, las palabras también por su sentido (Domínguez, 1985, p. 306).
Tal como lo señala Domínguez Caparros (y Quilis), la función rítmica de la rima parece exigir el final del verso, cuando hay encabalgamiento redobla su papel y ayuda a percibir el final de un verso. Pese al verso libre o semi-libre greiffiano, su poesía recurre a la rima como elemento versal e incluso aparece como una serie internas del verso, en un equilibro entre el ritmo y el sentido oracional y proposicional.

\section{Formas de la rima}

León de Greiff utiliza la mayoría de modalidades de rima descritas; sin embargo, su ubicación no sigue secuencias muy definidas e incluso lo hace de un modo alterado, atravesando un verso sin rima o duplicando algún 
sonido, así: en lugar de ABBA, AMBBA, o ABBBA.

Rima abrazada (ABBA): primera estrofa.

Rima cruzada (ABAB): aunque incompleta, en varias estrofas.

Rima continua (AAAAA): tercera estrofa.

Rima Pareada (AA): final de la primera estrofa.
Rima "eco": podríamos referirnos a la repetición de la frase /Es esta... /

Yo voy tocando mi vihuela por estas rutas sublunares

fijos los ojos en la estela de consonancias singulares...

Balada del trovero trashumante, León de Greiff

\section{Conclusiones}

La poesía de León de Greiff oculta un pentagrama en su escritura, dispone de una orquesta en su ejecución y reclama un lector con memoria de músico para percibir ese rugir de palabras, de pausas y encabalgamientos; de ritmos y chocar de sílabas, de imágenes y sucesos de otros mares; en definitiva, los algoritmos de la música de la poesía greiffiana nos invitan a la conjunción entre número, palabra y cuerpo. La música hecha verso es un alfabeto cifrado en secuencias de números secretos; la palabra y sus ritmos plagian ese erotismo incesante entre el agua y la roca, el ritmo obliga a los cuerpos con el transcurrir de los versos.

León de Greiff está dentro de la línea tradicional de aquellos poetas juglares que antes de comenzar el canto, piden para acompañarse un instrumento musical (zampoña, vihuela, guitarra mejor que lira), y un vaso de buen vino. Una vez en posesión del instrumento y de la bebida entona sus «trovas» que en él tendrán sabor viejo, popular, de relato que se dice a voces en una plaza en día de fiesta (Rodríguez, 1972b, p. 222).

\section{Referencias}

Domínguez, J. (2000). Métrica española. Madrid: Síntesis.

Domínguez, J. (1985). Diccionario de Métrica Española. Madrid: Paraninfo.

Farina A. (1920). En El Espectador (18 de diciembre). Citado por: Surdíaz Luis (1995): El múltiple rostro de León de Greiff. La Habana, Instituto cubano del libro.

Greiff, L. (1993). Obra poética. Caracas, Biblioteca Ayacucho. Selección y prólogo de Cecilia Hernández de Mendoza. Poema fechado en febrero de 1931. P. 111-113.

Greiff, L. (2004). Obra poética: Tergiversaciones (y poesía escrita entre 1913 y 1924). Tomo I. Bogotá, UNAL.

Mohler S. Ch. (1969). The poetic Style of León de Greiff. USA, The George Washington University.
Peterson, M. (2011). "The Plan of Heaven." Galileo's Muse: Renaissance Mathematics and the Arts, Harvard University Press, Cambridge, Massachusetts; London, England. pp. 69-80, www.jstor.org/stable/j.ctt24hj3z.7.

Rodríguez, O. (1972a). "Recursos rítmicos en la poesía de León de Greiff”. Thesaurus, Tomo XXVII, Número 3. Bogotá, Boletín del Instituto Caro y Cuervo. Centro Virtual Cervantes.

Rodríguez, O. (1972b). "León de Greiff: Imágenes y figuraciones de una poética de vanguardia”. Anales de literatura hispanoamericana. Madrid, UCM.

Vásquez, R. (1943). "La poesía de León de Greiff." En: Revista de las Indias, febrero. Bogotá, Imprenta Nacional. 